\title{
Design and Experimental Research on Sealing Structure for a Retrievable Packer
}

\author{
Yang Liu, ${ }^{1}$ Zhanghua Lian $\mathbb{D}^{1},{ }^{1}$ Junwen Chen, ${ }^{2}$ Shengping Kuang, ${ }^{3}$ Yisheng Mou, ${ }^{1}$ \\ and Yuhai Wang ${ }^{3}$ \\ ${ }^{1}$ State Key Laboratory of Oil and Gas Reservoir Geology and Exploitation, Southwest Petroleum University, \\ Chengdu 610500, China \\ ${ }^{2}$ China Petroleum Engineering and Construction Corp. Southwest Company, Chengdu 610041, China \\ ${ }^{3}$ TLM Oilfield Company, CNPC, Korla, Xinjiang 841000, China
}

Correspondence should be addressed to Zhanghua Lian; lianzh1964@sina.com

Received 23 November 2019; Revised 23 April 2020; Accepted 1 May 2020; Published 19 May 2020

Academic Editor: Reza Kolahchi

Copyright ( 2020 Yang Liu et al. This is an open access article distributed under the Creative Commons Attribution License, which permits unrestricted use, distribution, and reproduction in any medium, provided the original work is properly cited.

In order to reduce the failure accidents of conventional packers, a kind of sealing structure of retrievable packers is designed, which can provide reference for optimizing the sealing performance and pressure capacity of packers. And theoretical calculation and experimental research on their sealing performance and pressure capacity are carried out through the finite element analysis on the contact with large deformation based on Abaqus and experimental study. The results show that the upper packer is subjected to greater stress and mainly plays a sealing role in the sealing process. In order to improve the sealing performance of the packer, the height of the upper and lower packer should be preferentially selected about $60 \mathrm{~mm}$, the height of the middle rubber cylinders should be about $50 \mathrm{~mm}$, and the thickness of the packer should be about $21 \mathrm{~mm}$. The newly designed rubber cylinders can meet $150^{\circ} \mathrm{C}$. The newly designed rubber cylinders can meet the sealing function and pressure bearing function under the condition of 10,000 Psi and $150^{\circ} \mathrm{C}$. The newly designed rubber cylinder can satisfy the function of sealing and pressure-bearing under $140^{\circ} \mathrm{C}$ and 10,000 Psi. The whole experiment shows that the capacity of bearing pressure and sealing is stable, which can better meet the requirements of field use.

\section{Introduction}

With the increase of energy demand, the exploitation and storage technology of oil and gas have been developed rapidly $[1,2]$. Packer is an important product used in oil and gas production. It mainly consists of the anticollision part, seating part, locking part, sealing part, anchoring part, and unloading part. The seating part is mainly composed of rubber parts. Some scholars have done relevant research on its material and structure. Chen et al. [3-7] found that high-pressure packer test (HPPT) is an enhanced constant head packer test for characterizing the permeability or coupled hydromechanical properties of fractured rocks under high-pressure groundwater flow conditions. Zhu et al. [8-10] studied that performances of rubber materials have a direct relationship with the sealing function of packers. Li et al. [11, 12] got the observations results of packers on initiation fracture through carrying out a set of laboratory hydraulic fracturing experiments. He et al., Tong et al., and Chen et al. [13-15] studied that hydrogenated acrylonitrile butadiene rubber (HNBR) was chosen to develop peroxide cured and carbon black N220-reinforced highmodulus vulcanizates with possible applications in packers for oil exploration. Moon et al. [16-19] studied that the effect of anisotropic characteristics of the jointed rock mass around a packer interval is also discussed through a numerical parametric study using the distinct element method. Hu et al. [20] found that the stresses concentrated at the shoulder and inner vertex of the sealing ring have direct impact on the damage of the sealing rings under operational conditions. Dobrotă et al. [21-24] found the duration of the refining process transformation of the rubber waste reclaiming process into a sustainable one by obtaining the new type of reclaimed rubber. 
In consideration of the analysis results of the above scholars and experts, the failure reasons of conventional packers are analyzed in this paper, a desirable sealing structure of packers is designed, and theoretical calculation and experimental research on their sealing performance and pressure capacity are carried out, so as to provide certain data support for the design and safe use of packers.

\section{Structure and Working Principle of a Retrievable Packer}

In the oil and gas well, sealing the formation through the packers provides a gas passage way for oil and gas at project formation, as shown in Figure 1.

In the sealing process of the conventional packer, the pressure head goes down firstly, the middle support ring moves down, and the rubber ring will be extruded. If the force is too large, plastic deformation will occur, and the elastic deformation will be lost in the process of bottom hole sealing for a long time. The chamfer position of the pressure ring and support ring here will cause the rubber cylinder to protrude, which is more prone to failure and may not necessarily occur in the contact position, but this structure helps to fix the rubber cylinder. There is a "mutation" area, which is prone to failure or shedding, as shown in Figure 2.

The retrievable packer studied in this paper is a mechanical seating packer. It is a recyclable packer. The packer with two-way slips can be seated in tension, compression, or medium state and can withstand the pressure difference from top to bottom. The design of large bypass holes in the packer can reduce swabbing effect during downloading and recycling and automatically close when the tool is seated. When the packer is unpacked, the bypass hole is opened firstly, the upper and lower pressure is balanced, and the upper slip is released. The slip release device on the packer can reduce the resistance of the recovery tool. A schematic diagram of the structure of the preferable packer studied is shown in Figure 3 in this paper.

The retrievable packer needs to be completed by using the sealing element under the external force. The sealing element acts under the action of the axial force to seal the annular clearance and prevent the passage of high-pressure mud. As the key core component of the retrievable packer, the elastic seal body is made into a cylinder shape and also becomes a rubber cylinder.

\section{Sealing Structure Design and Finite Element Calculation}

3.1. Force Analysis of the Rubber Cylinder. The rubber cylinder does not bear the corresponding axial force and torque during the normal lowering process. When the pressure of the rubber cylinder reaches a certain value, the seat shear nails connecting the inner sleeve and the upper jacket of the packer are cut off. The packer begins to realize the seat seal [25]. The outer sleeve starts to slide and compress the rubber cylinder under the gravity of the upper tube pipe itself so that the rubber cylinder is compressed and expanded; thus, the rubber cylinder is compressed and expanded. Contact with

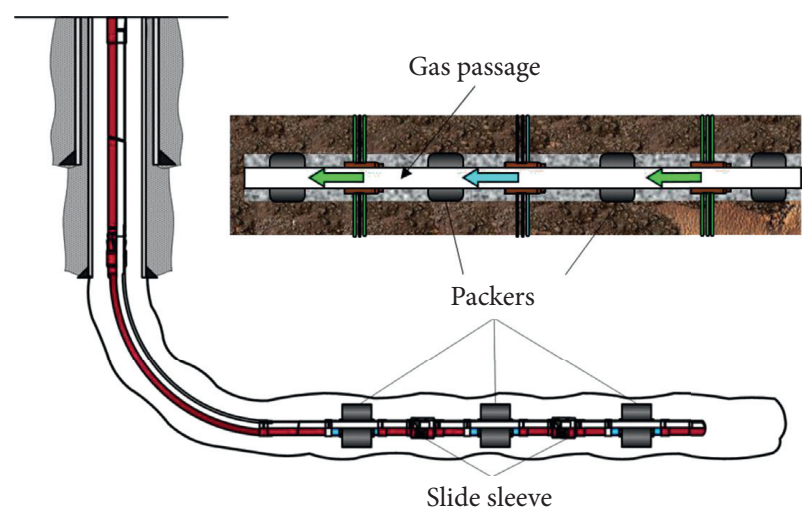

FIGURE 1: Work mechanical of packer rubber.

external casing can realize the sealing function of the outer annulus of the tube pipe. The implementation process is shown in Figure 4.

3.2. Shape and Dimension Design. The determination of the height of the rubber cylinder mainly considers the shear effect of the compression rubber cylinder of the packer. When the compression rubber cylinder is working in the downhole stratum, the shear effect is caused by the sealing pressure difference between the top and bottom of the rubber cylinder. The shear effect diagram is shown in Figure 5.

The shear stress generated after the seating can be calculated according to the following equilibrium equation [25]:

$$
\left.2 \pi R_{2} h \sigma_{r}\right|_{r=R_{2}} f+2 \pi R_{1} h \tau=\Delta P \pi\left(R_{2}^{2}-R_{1}^{2}\right) .
$$

From formula fd1(1),

$$
h=\frac{\Delta P\left(R_{2}^{2}-R_{1}^{2}\right)}{2 R_{1}[\tau]+2 R_{2} f\left(P_{1} \mu / 1-\mu\right)} .
$$

In the formula, $[\tau]$ is the permissible shear stress of compressed rubber cylinder material and $f$ is the friction coefficient between the rubber tube and the wellbore.

NBR is used as the material of the compression rubber cylinder. Because rubber is a nonlinear elastic material, different formulations of rubber have a great influence on the properties of the rubber material.

The properties of standard samples of vulcanized nitrile butadiene rubber were tested under different temperatures and pressures. Finally, the parameters of the rubber material were determined, and the allowable shear stress and shear stress of the rubber material were obtained $[25,26]$. The relevant data are shown in Table 1.

According to Table 1, it can be seen that the height of the rubber cylinder will change significantly with the difference of allowable shear stress and friction coefficient of rubber. Figure 6 shows that when the allowable shear strength is constant, the height of the rubber cylinder decreases gradually with the increase of friction coefficient, and the slowdown trend decreases gradually. Under the same friction coefficient, the higher the allowable shear stress of the 

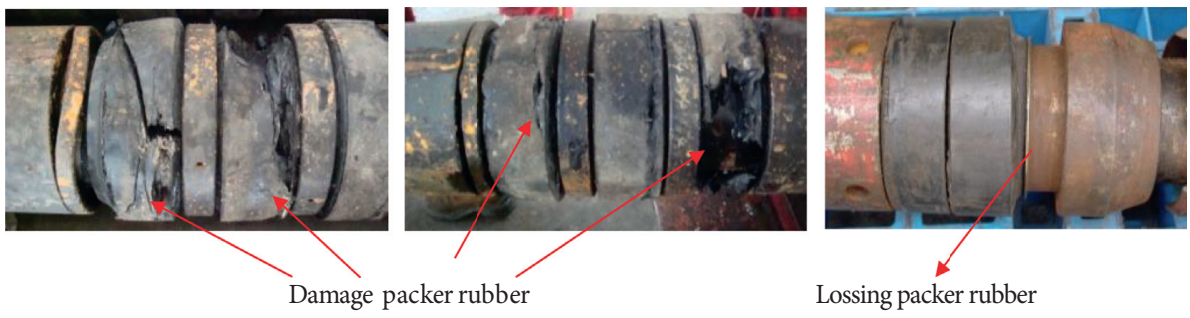

FIgURE 2: Failure cases of the rubber packer.
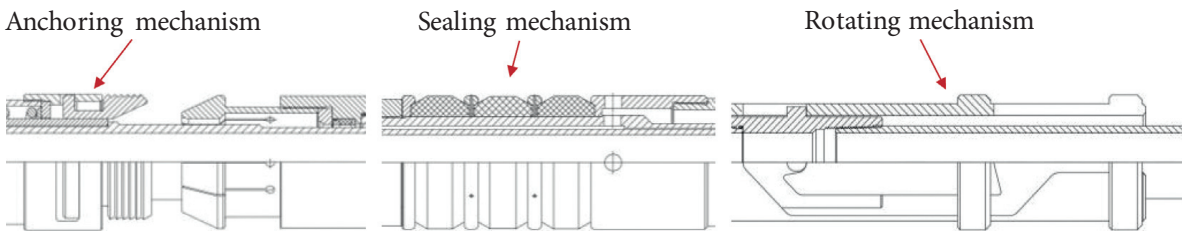

(a)

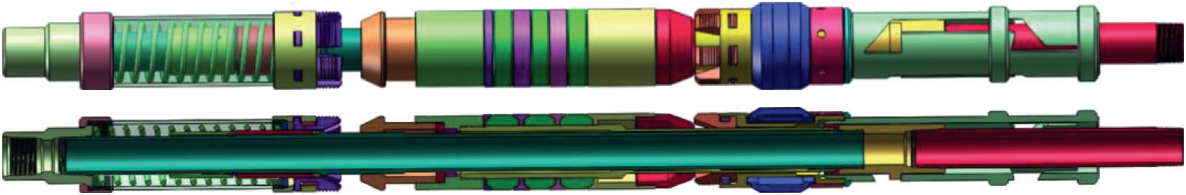

(b)

Figure 3: Structural schematic diagram of the retrievable packer of high temperature and high pressure. (a) Two-dimensional assembly diagram of retrievable packers. (b) Three-dimensional assembly of retrievable packers.

rubber material, the smaller the height of the rubber cylinder. When the friction coefficient is greater than 0.3 , the permissible shear strength of the rubber cylinder has little effect on the height.

\subsection{Calculation of Sealing Force of the Rubber Cylinder Seat.} Compressive rubber cylinder deformation analysis is completed in two stages. The first stage is the process from rubber cylinder deformation to contact wellbore, and the second stage is the process of increasing load after rubber cylinder contact to make it more close to the wellbore. In the first stage, it is assumed that the radial deformation is symmetrically distributed throughout the height, and the volume compression of the rubber cylinder does not exceed the elastic limit of the rubber material. The differential equation can be obtained by removing the higher-order differential terms:

$$
\left(1+\varepsilon_{z}\right) \frac{\partial u}{\partial r}+\left(1+\varepsilon_{z}\right) \frac{u}{r}=-\varepsilon_{z}
$$

The general solution of equation (3) can be obtained:

$$
u=\frac{-\varepsilon_{z} r}{2\left(1+\varepsilon_{z}\right)}+\frac{\psi_{1}(z)}{r} \text {. }
$$

$\psi_{1}(z)$ can be obtained by the following boundary conditions:

$$
r=R_{0}, u=0 ; \text { in that way, } \psi_{1}(z)=\frac{\varepsilon_{\mathrm{z}} R_{0}^{2}}{2\left(1+\varepsilon_{z}\right)} .
$$

The maximum allowable clearance equation can be obtained by introducing $\psi_{1}(z)$ into (4):

$$
u=\frac{\varepsilon_{z}}{2\left(1+\varepsilon_{z}\right)}\left(\frac{R_{0}^{2}}{r}-r\right)
$$

$\varepsilon_{z}$ can be obtained by the following boundary conditions:

$$
r=R_{1}, u=u_{0} \text {; in that way, } \varepsilon_{z}=\frac{2 u_{0} R_{1}}{R_{0}^{2}-R_{1}^{2}-2 u_{0} R_{1}} .
$$

Since the axial deformation of rubber used in rubber cylinder seals must be less than the allowable axial deformation, the following relationship exists:

$$
\varepsilon_{z}=\frac{2 u_{0} R_{1}}{R_{0}^{2}-R_{1}^{2}-2 u_{0} R_{1}}<[\varepsilon] .
$$

In the formula, $[\varepsilon]$ is the relative axial deformation allowed for the rubber cylinder, $\%$; $[\varepsilon]$ can be determined by the test method. Its value mainly depends on the material used in the rubber cylinder and the specific working conditions.

The maximum allowable clearance obtained by formula (8) is

$$
u_{0 \max } \leq \frac{[\varepsilon]}{2(100-[\varepsilon])}\left(R_{1}-\frac{R_{0}^{2}}{R_{1}}\right)
$$

The corresponding stress values can be obtained according to generalized Hooke's law: 

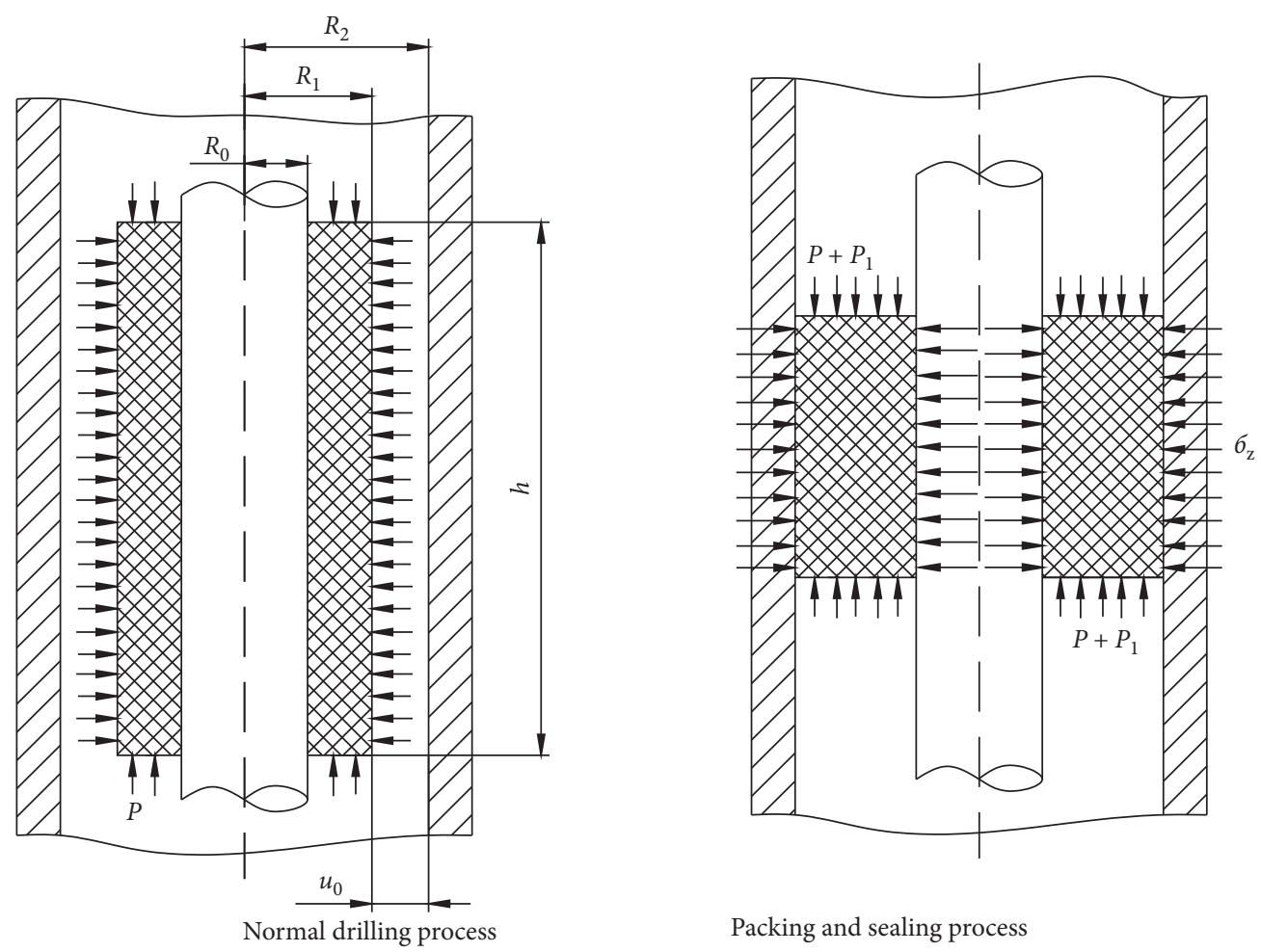

Packing and sealing process

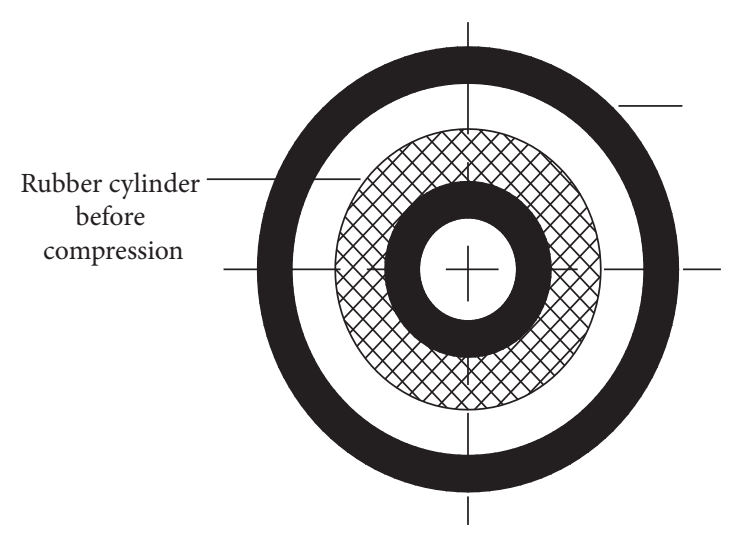

(a)

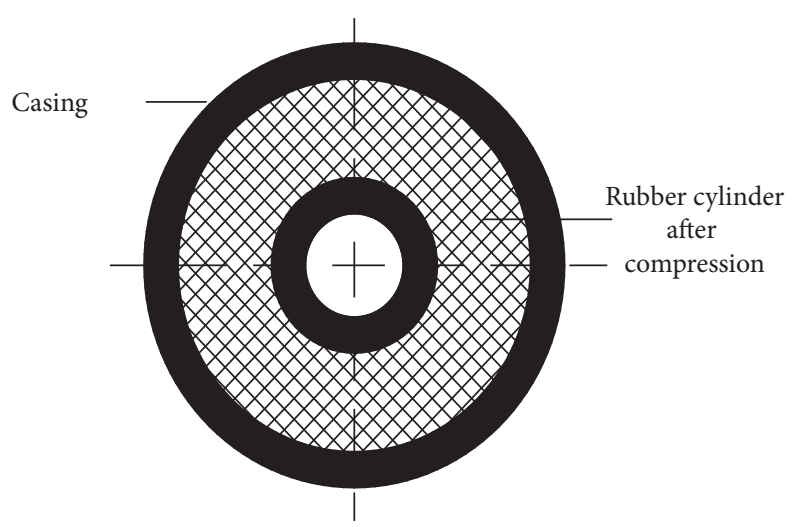

(b)

FiguRE 4: Force sketch and cross section of the rubber cylinder. (a) Force sketch of the rubber cylinder. (b) The rubber cylinder before and after compression.

$$
\left.\begin{array}{l}
-\sigma_{r}=\lambda \frac{\varepsilon_{z}}{1+\varepsilon_{z}}-2 G \frac{\varepsilon_{z}}{2\left(1+\varepsilon_{z}\right)}\left(1+\frac{R_{0}^{2}}{r^{2}}\right) \\
-\sigma_{\theta}=\lambda \frac{\varepsilon_{z}}{1+\varepsilon_{z}}+2 G \frac{\varepsilon_{z}}{2\left(1+\varepsilon_{z}\right)}\left(\frac{R_{0}^{2}}{r^{2}}-1\right) \\
-\sigma_{z}=\lambda \frac{\varepsilon_{z}^{2}}{1+\varepsilon_{z}}+2 G \varepsilon_{z}
\end{array}\right\},
$$

where $G=E / 2(1+\mu)$ and $\lambda$ is Lame coefficient, $\lambda=E \mu /(1+\mu)(1-2 \mu)$.
In the second stage, the rubber cylinder is close to the wellbore due to the further increase of the load. At this time, the deformation of the rubber cylinder depends on the stiffness of the outer sleeve and the wellbore of the packer. Because the deformation of the rubber cylinder does not exceed the yield limit of the material, the elastic modulus of three materials (outer sleeve, rubber cylinder, and borehole rock) is obviously different, and the radial and circumferential deformation of the rubber cylinder after contact with the borehole rock is neglected. Its mathematical expression is as follows (as shown in Figure 5):

$$
\varepsilon_{r}=\varepsilon_{\theta}=0 \text {. }
$$

According to generalized Hooke's law, we can find that 

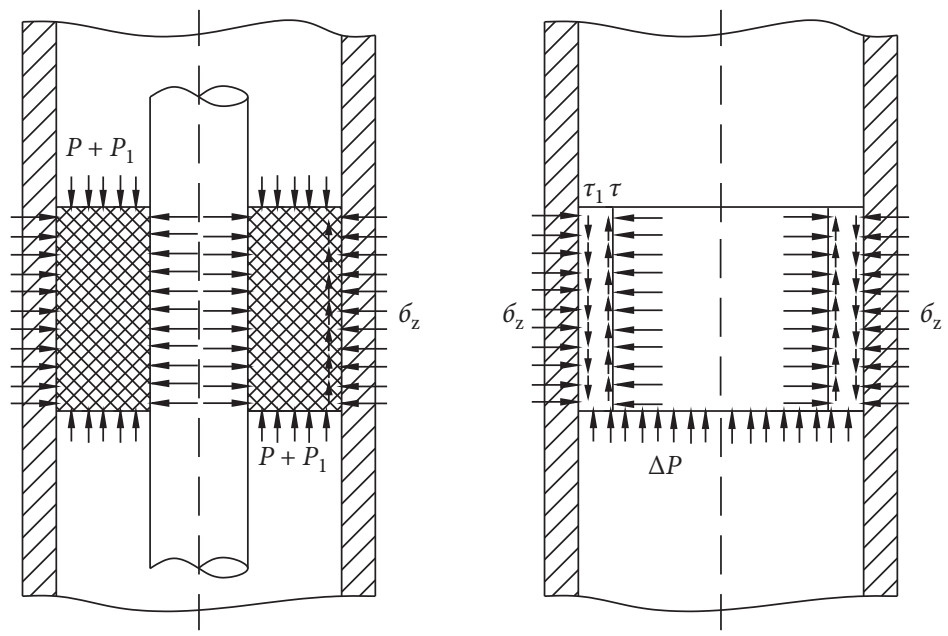

FIGURE 5: Shear effect diagram after sealing of the rubber cylinder.

TABLe 1: Height of the rubber cylinder under different permissible shear stress and friction coefficients $(f)$.

\begin{tabular}{lccccccccc}
\hline$\tau(\mathrm{MPa})$ & & & & $F$ & & & \\
& 0.1 & 0.15 & 0.2 & 0.25 & 0.3 & 0.35 & 51 & 45 & 40.4 \\
\hline 1 & 152 & 109 & 85 & 70 & 59 & 49 & 44 & 39 \\
2 & 138 & 101 & 80 & 66 & 57 & 48 & 36 \\
3 & 126 & 95 & 76 & 64 & 55 & 48 & 38 \\
4 & 116 & 89 & 72 & 61 & 53 & 46 & 41 & 37 \\
\hline
\end{tabular}

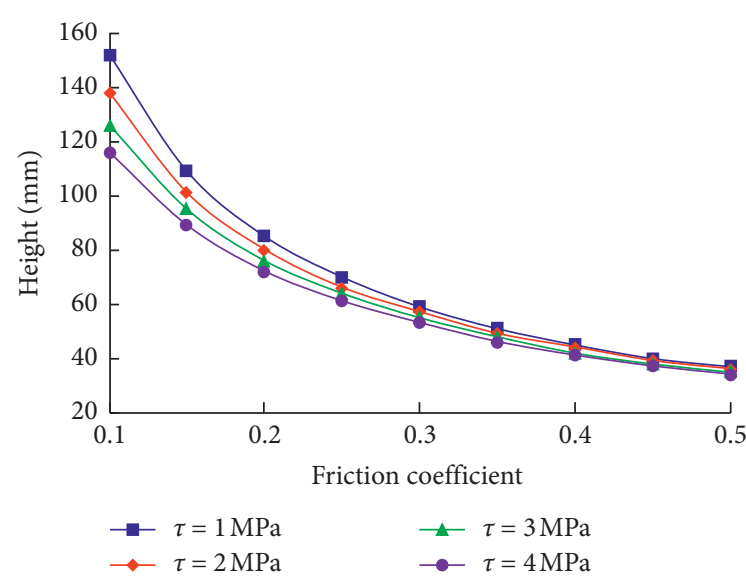

FIGURE 6: The height of the rubber cylinder varies with shear stress under different friction coefficients.

$$
\sigma_{z}=P_{1}=\left.\frac{1-\mu}{\mu} \sigma_{r}\right|_{r=R_{2}} .
$$

In order to ensure the specific pressure $\left(P_{1}\right)$ on the end face of the sealing cylinder under the action of pressure difference $\Delta P$, the relationship between radial specific pressure and $\Delta P, P_{1}=f(\Delta P)$, which can effectively seal, can be determined according to the experimental method: $\left.\sigma_{r}\right|_{r=R_{2}} \geq P_{1}$.

According to the force analysis of the front compressed rubber cylinder, the total specific pressure applied on the sealing rubber cylinder is the sum of the axial force of the rubber cylinder of the two stages, that is,

$$
P^{*}=P+P_{1}=\frac{\lambda \varepsilon_{z}^{2}}{1+\varepsilon_{z}}+2 G \varepsilon_{z}+\left.\frac{1-\mu}{\mu} \sigma_{r}\right|_{r=R_{2}} .
$$

From the above formula, it can be seen that the axial load affecting the packer is mainly related to the pressure difference of the packer seal, the original clearance between the sealant cylinder and the seat casing, and the size of the rubber cylinder itself.

3.4. Material Constants and Constitutive Relations of NBR. In this paper, the material used in the rubber cylinder is NBR. The rubber material used in NBR is suitable for Yeoh model (reduced polynomial hyperelastic model). The stress-strain data of the rubber material at all temperatures are brought into Abaqus finite element analysis software for fitting. In the process of fitting, the Yeoh model is selected to judge after fitting [27]. The material constants of Yeoh model rubber at five temperatures can be obtained as shown in Table 2.

As a strain energy function, Gregory believes that the Mooney-Rivlin model does not take enough high-order terms into account, so the theoretical results of its prediction are quite different from the experimental data [26-28]. Therefore, a third-order expression is proposed:

$$
\begin{aligned}
W= & C_{10}\left(I_{1}-3\right)+C_{01}\left(I_{2}-3\right)+C_{20}\left(I_{1}-3\right)^{2} \\
& +C_{11}\left(I_{1}-3\right)\left(I_{2}-3\right)+C_{30}\left(I_{1}-3\right)^{3} .
\end{aligned}
$$

The research shows that $\partial W / \partial I_{2}$ is far less than $\partial W / \partial I_{1}$ and approximately equal to zero. So, Yeoh assumes $\partial \mathrm{W} / \partial \mathrm{I}_{2}$ is zero. Formula (14) is derived from $I_{2}$ by taking partial derivation: 
TABLE 2: Material constants of the Yeoh model for two rubber materials at five temperatures.

\begin{tabular}{lccc}
\hline Material constants & $\mathrm{C}_{10}(\mathrm{~Pa})$ & $\mathrm{C}_{20}(\mathrm{~Pa})$ & $\mathrm{C}_{30}(\mathrm{~Pa})$ \\
\hline $7-30$ & 939840.85 & 284971.93 & 79314.0152 \\
$7-60$ & 2539782.67 & -1816140.36 & 1246021.2 \\
$7-90$ & 1804782.6 & -534617.057 & 560936.07 \\
$7-120$ & 1692499.74 & -489353.895 & 918409.019 \\
$7-150$ & 1755887.92 & -576447.31 & 897236.305 \\
$8-30$ & 1455627.61 & 131108.146 & 929565.95 \\
$8-60$ & 1438504.43 & -342433.01 & 1202324.23 \\
$8-90$ & 1987618.3 & -989854.139 & 2064562.35 \\
$8-120$ & 2038447.57 & -808712.075 & 1754438.74 \\
$8-150$ & 2001848.94 & -526508.69 & 1453226.66 \\
\hline
\end{tabular}

$$
W=C_{10}\left(I_{1}-3\right)+C_{20}\left(I_{1}-3\right)^{2}+C_{30}\left(I_{1}-3\right)^{3} .
$$

Mooney-Rivlin model can better reflect the stress and strain of rubber under tensile deformation, but it is difficult to describe other deformations, especially compression deformation. Therefore, this paper intends to use the Yeoh model to complete the finite element analysis of the rubber cylinder.

3.5. Analysis Model of the Packer Rubber Cylinder. In order to verify the seating performance and pressure-bearing capacity of the sealing part of the retrievable packer, theoretical calculation and experimental study are needed. The following are the model of the sealing part of the retrievable packer and the basic size parameters of the packer rubber cylinder.

In this paper, two types of rubber cylinders, $65 \mathrm{~mm}$ and $92 \mathrm{~mm}$, are selected in the analysis process. In the first group, the inner diameter of the rubber cylinder is $104.6 \mathrm{~mm}$, the outer diameter of the rubber cylinder is $146 \mathrm{~mm}$, the length of the single rubber cylinder is $65 \mathrm{~mm}$, the outer diameter of the upper and lower pressure ring is $140 \mathrm{~mm}$, the inner diameter of the upper and lower pressure ring is $102 \mathrm{~mm}$, the seating pressure is $25 \mathrm{MPa}$, and the inner diameter of the seating casing is $166.5 \mathrm{~mm}$ as shown in Figure 7. In the second group, except for the length of the single rubber cylinder is $92 \mathrm{~mm}$, all other conditions are the same as the first group. Friction coefficient between the rubber cylinder and the seating section has a great influence on the process of force analysis of the rubber cylinder. In this paper, the force and deformation of the rubber cylinder with a friction coefficient of $0.1,0.2,0.3,0.4$, and 0.5 are analyzed, respectively.

Because the main analysis of the deformation of the rubber cylinder is that the separating ring and adjusting ring belong to alloy steel and the elastic modulus is relatively large, so this paper sets the separating ring and adjusting ring as the rigid body. According to the structure and size of the rubber cylinder at assembly state, the contact pair between the rubber cylinder and metal parts is established. The outer cylinder and the inner cylinder are fixed equally, and the lower adjusting ring is fixed equally. Fixed, the upper adjusting ring establishes the reference point for loading. The finite element model and the loading model of the rubber cylinder are shown in Figure 8.

3.6. Analysis of Results. Assuming that the temperature is $150^{\circ} \mathrm{C}$ in the well of $5,000 \mathrm{~m}$ and the hardness of the rubber material is 70, Figures 9 and 10 are von Mises stress contours of the two length rubber cylinder models with a friction coefficient of 0.3 and loading displacement of $40 \mathrm{~mm}$.

When the temperature is $150^{\circ} \mathrm{C}$ in the downhole and the hardness of the rubber material is 70 as shown in Figure 9, the rubber cylinder gradually decreases and expands with the increase of time. The faster the deformation time of the rubber cylinder increases, the faster the deformation of the rubber cylinder begins to occur. The first rubber cylinder that contacts seals is the first rubber cylinder. For $t=7 \mathrm{~s}$, the middle and lower rubber cylinders begin to contact with the casing. It is found that the maximum stress of the three rubber cylinders is in the position where the ring and the rubber cylinder are extruded. It is easy to fail here. When $t=9 \mathrm{~s}$, the maximum stress is $50.85 \mathrm{MPa}$. The first rubber cylinder is subjected to the greatest stress and the most serious deformation.

Figure 10 shows that the maximum von Mises stress of the rubber cylinder is $162.4 \mathrm{MPa}$ when the length of the rubber cylinder is $92 \mathrm{~mm}$, and it occurs in the upper part of the outer surface of the rubber cylinder, and the phenomenon of stress concentration is obvious. When the pressure is large enough, the region deforms and fails firstly, and the phenomenon of "protrusion" of the rubber cylinder occurs. In addition, the larger stress area occurs on the inner surface of the rubber cylinder. In the middle area, the stress distribution on the inner surface of the rubber cylinder is "small at both ends and large in the middle." After compression, the deformation presents a "lunar" distribution. The rubber cylinder deforms to the same side, and the middle deformation is the largest. When the displacement is the same, the von Mises stress of the short rubber cylinder is larger than that of the long rubber cylinder. At the same time, it can be found that when the displacement is not large enough, the rubber with the height of $92 \mathrm{~mm}$ does not contact the borehole wall.

From Figure 11, it can be seen that there is no linear relationship between the increase of contact pressure and the increase of loading displacement. When the loading displacement is $45 \mathrm{~mm}$, the contact pressure in the upper cylinder sealing area is $4.4-9.4 \mathrm{MPa}$, the contact pressure in the middle cylinder sealing area is $2.2-3.8 \mathrm{MPa}$, while the pressure in the lower cylinder sealing area is $0.8-1.7 \mathrm{MPa}$, and the contact pressure in the upper cylinder sealing area is 4.4-9.4 $\mathrm{MPa}$. The contact pressure is greater than the contact pressure of the middle rubber cylinder, and the contact pressure of the middle rubber cylinder is greater than the contact pressure of the lower rubber cylinder. The contact pressure difference between the three rubber cylinders increases with the increase of loading 


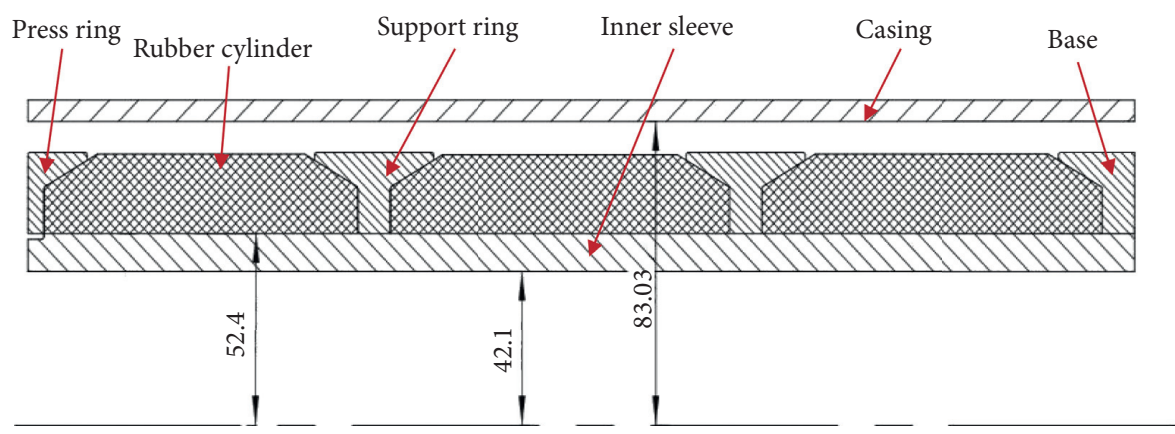

FIGURE 7: Structure dimensions of sealing parts.
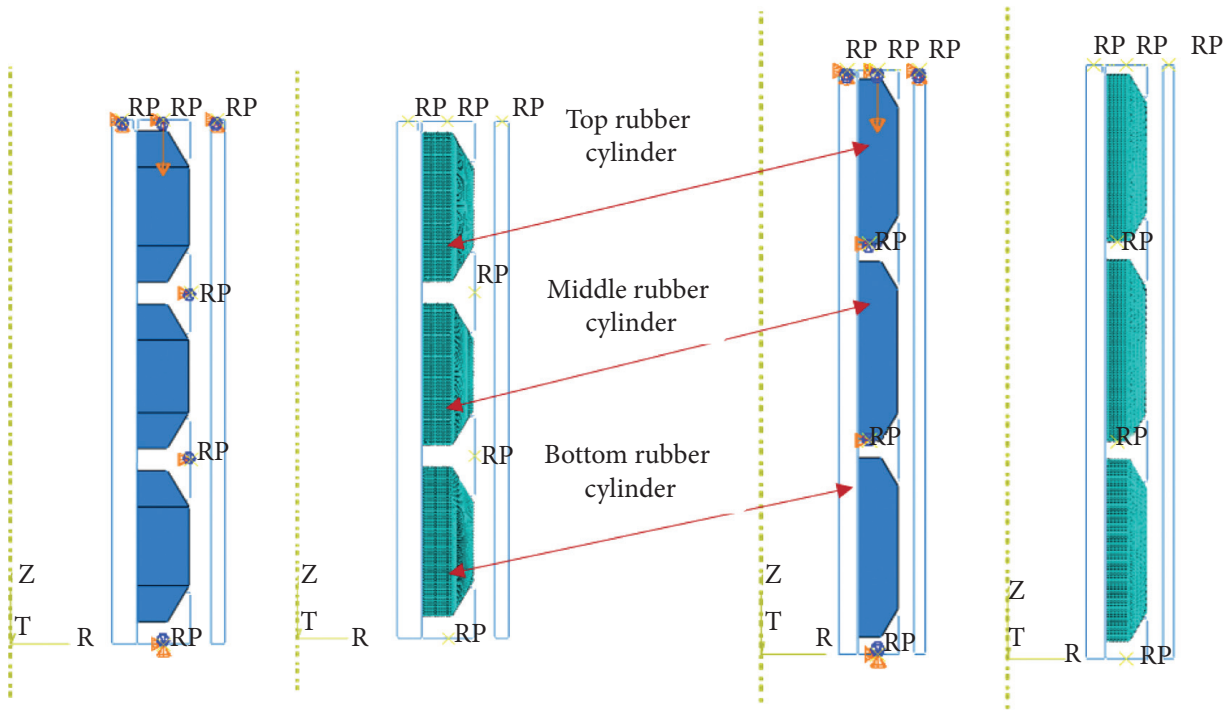

Figure 8: Rubber cylinders and finite element models.

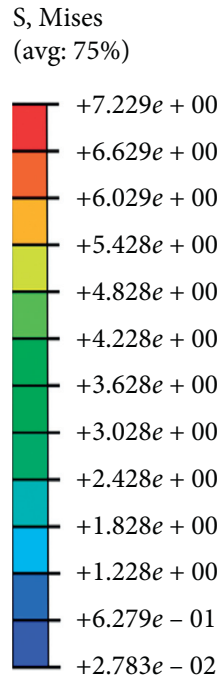

(a)

\section{S, Mises}

(avg: 75\%)

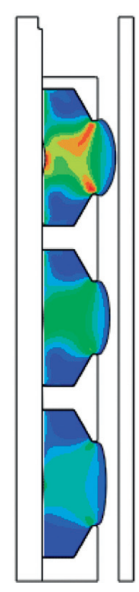

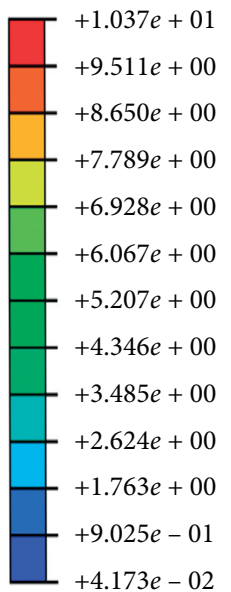

(b)
S, Mises
(avg: $75 \%)$

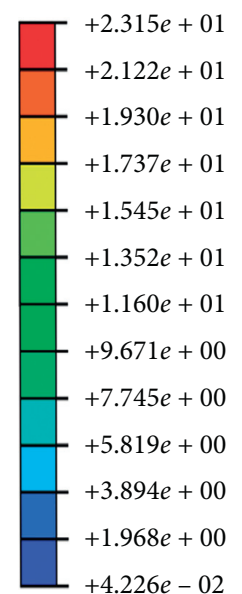

(c)
S, Mises

(avg: 75\%)
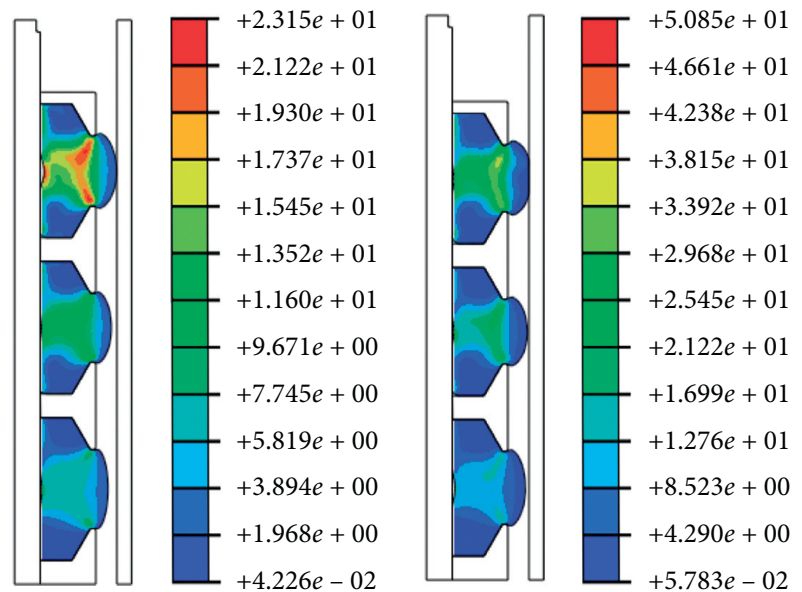

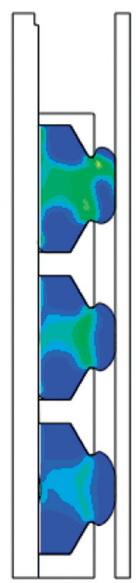

(d)

FIgURE 9: Stress change of the short rubber cylinder at different seating times. (a) $t=3 \mathrm{~s}$. (b) $t=5 \mathrm{~s}$. (c) $t=7 \mathrm{~s}$. (d) $t=9 \mathrm{~s}$.

displacement. When the loading displacement is small, the contact pressure in the sealing area of the three rubber cylinders does not change much, and the contact pressure of the three rubber cylinders varies from 0.3 to $1.1 \mathrm{MPa}$.
It can be seen that the greater the friction coefficient is, the greater the maximum contact pressure on the rubber cylinder is, as shown in Figure 12. The contact pressure in the sealing area of the upper, middle, and lower rubber 


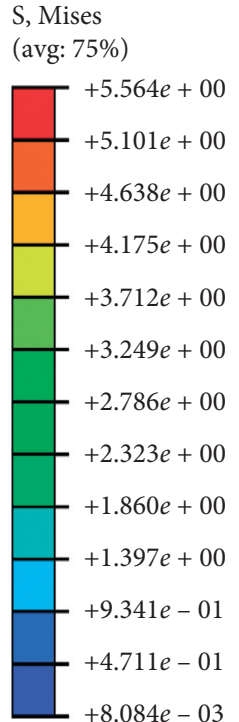

(a)
S, Mises (avg: $75 \%$ )

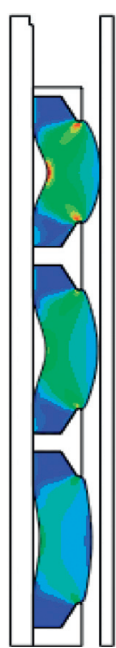

S, Mises (avg: $75 \%$ )

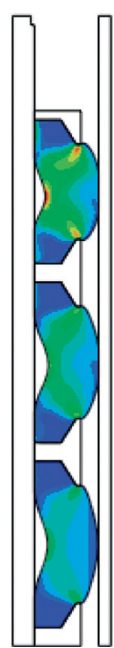

(b)

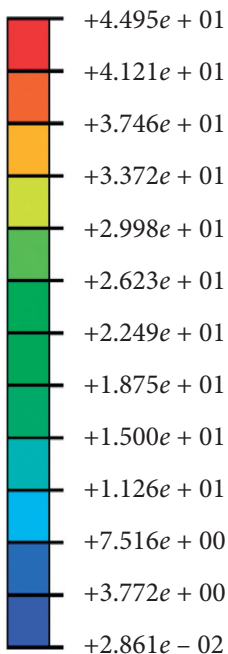

(c)
S, Mises (avg: $75 \%$ )
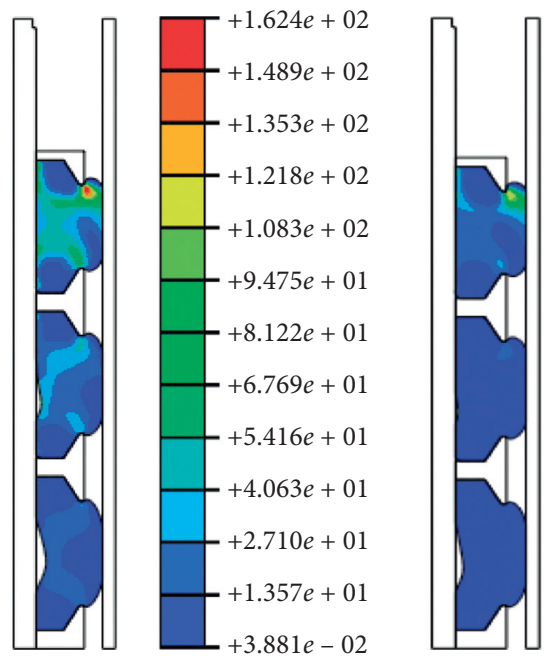

(d)

Figure 10: Stress change of the long rubber cylinder at different seating times. (a) $t=3 \mathrm{~s}$. (b) $t=5 \mathrm{~s}$. (c) $t=7 \mathrm{~s}$. (d) $t=9 \mathrm{~s}$.

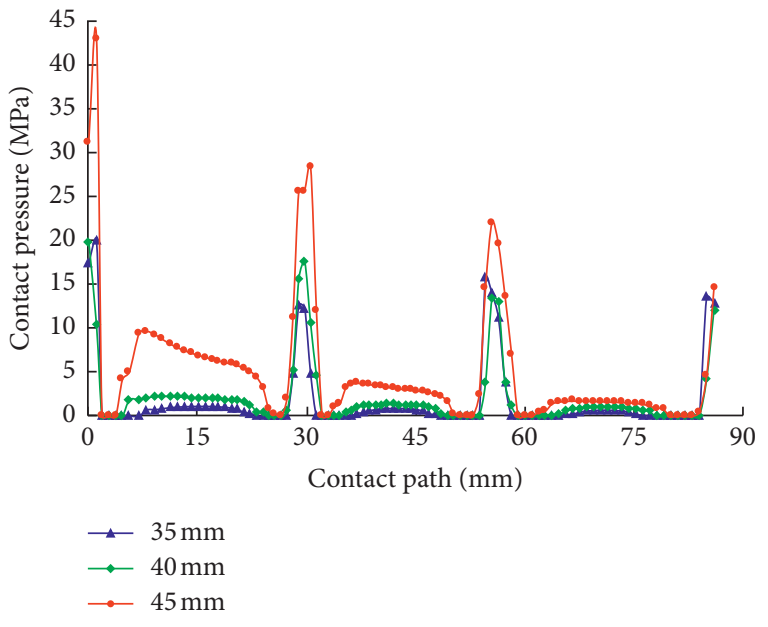

FIGURE 11: Change curves of contact pressure under different displacements.

cylinders increases with the increase of the friction coefficient. The contact pressure of the upper rubber cylinders increases the most, while the contact pressure of the middle rubber cylinders and the lower rubber cylinders increases little with the increase of the friction coefficient. It can be inferred that the top rubber cylinder plays the main role in the sealing process between the wellbore and the rubber cylinder of the removable packer.

According to Figure 13, the contact pressure of the two hardness rubber cylinders is the largest at $60^{\circ} \mathrm{C}$, the smallest at $30^{\circ} \mathrm{C}$, and the contact pressure is little affected by temperature at $90^{\circ} \mathrm{C}, 120^{\circ} \mathrm{C}$, and $150^{\circ} \mathrm{C}$. In high-temperature wells with temperature reaching a certain value, the contact pressure is gradually weakened due to the change in mechanical properties of rubber materials caused by temperature change. As the temperature increases with the increase of the wellbore

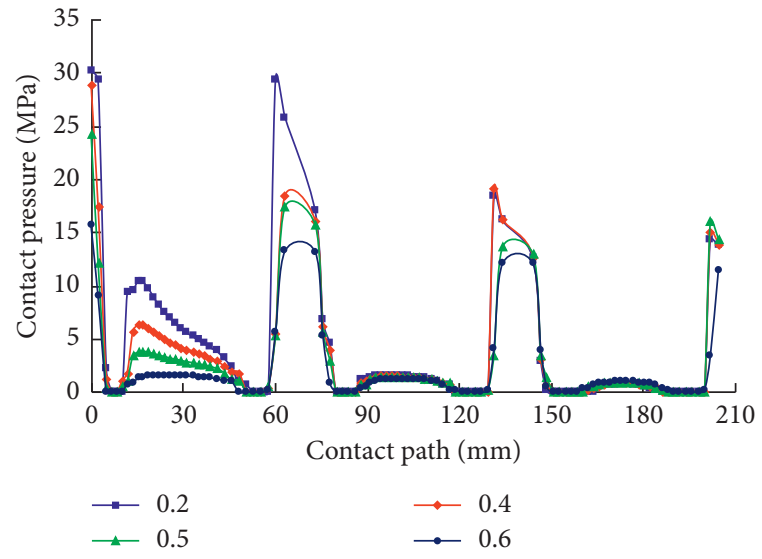

FIGURE 12: Change curves of contact pressure under different friction coefficients.

structure, it can be considered that the sealing contact pressure of preferable packers is affected by temperature in deep and ultradeep wells. The effect is small, but the effect of temperature is large when sealing is carried out in the shallow wellbore.

In order to verify the sealing performance of the rubber cylinder, the working pressure difference can be withstood. It is necessary to verify the specific pressure of the rubber cylinder. If the specific pressure is too small, the sealing surface will be detached, and the sealing performance will be unstable. If the specific pressure of the seal is too high, the contact surface may be damaged because of friction. In the design of the sealing structure, there are detailed standards for the specific pressure of rubber. For rubber with medium hardness, the formula for calculating the specific pressure of rubber is $[29,30]$

$$
Q_{\mathrm{MF}}=\frac{(0.4+0.6 \mathrm{PN})}{\sqrt{b_{\mathrm{M}} / 10}} .
$$




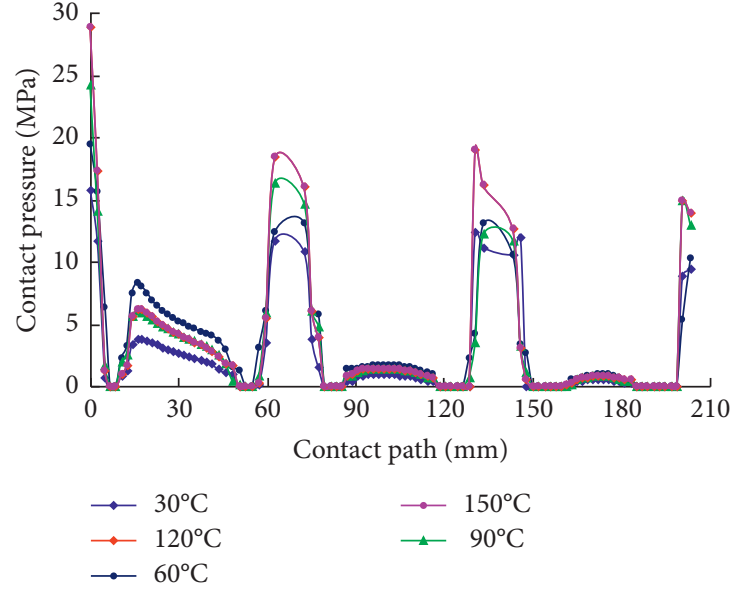

(a)

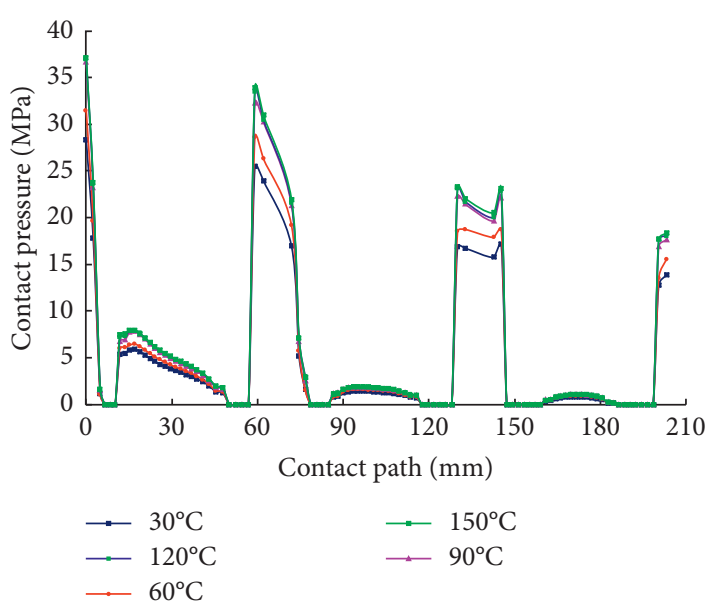

(b)

Figure 13: The contact pressure curves at different temperatures and hardness. (a) The hardness of the rubber cylinder is 70 . (b) The hardness of the rubber cylinder is 80 .

In the formula, $Q_{\mathrm{MF}}$ is the specific pressure of the middle seal, $\mathrm{PN}$ is the working pressure difference, $\mathrm{MPa}$, and $b_{\mathrm{M}}$ is the effective length of the seal, $\mathrm{mm}$.

Through the discussion of the factors affecting the contact pressure, it can be seen that the contact pressure at the sealing location is greatly affected by the loading displacement and friction coefficient. In this paper, the length of the rubber tube is $60 \mathrm{~mm}$, the friction coefficient between the borehole wall and the rubber cylinder is 0.3 , the temperature at the bottom of the well is $150^{\circ} \mathrm{C}$, and the loading displacement is $45 \mathrm{~mm}$. The effective contact length and average contact pressure are calculated by using the extracted contact pressure. By comparing the contact pressure and sealing specific pressure, it is determined whether the rubber cylinder can seal the pressure difference of $35 \mathrm{MPa}$. The effective contact length of the rubber cylinder is $136 \mathrm{~mm}$, and the average contact pressure is $6.1 \mathrm{MPa}$. The calculation of sealing specific pressure is as follows:

$$
Q_{\mathrm{MF}}=\frac{(0.4+0.6 \times 35)}{\sqrt{136 / 10}}=5.8 \mathrm{MPa} .
$$

From the above calculation, it can be seen that the average contact pressure is greater than the sealing specific pressure. Because the friction coefficient between borehole wall and sealing rubber, that is, the friction coefficient between rubber and rock, is generally greater than 0.3 , the above calculation is safe. Rubber will be destroyed when the contact pressure is larger than the allowable specific pressure of NBR. Therefore, when keeping the pressure difference between upper and lower rubber, the height of the rubber cylinder can be increased appropriately, and the effective sealing length between the rubber cylinder and the wellbore can be increased. When the length of the rubber cylinder is too long, the contact pressure will be affected. Because of its size, the length of the rubber cylinder is not easy to increase too long on the basis of $60 \mathrm{~mm}$.

\section{Study on Optimization of Seal Structure Size}

According to the design theory of the packer rubber cylinder, the influence of the rubber cylinder chamfer on the force of the rubber cylinder is greater. The existing theory and experimental verification show that when the rubber cylinder chamfer is $30^{\circ} \sim 50^{\circ}$, it is easy to produce "protrusion" phenomenon, which minimizes the stress concentration of the rubber cylinder. In this paper, the rubber cylinder chamfer is $45^{\circ}$. In the design of rubber cylinder assembly, the height of upper and lower rubber cylinders is the same, and the height of the middle rubber cylinder is less than that of upper and lower rubber cylinders [31]. The design size diagram of the rubber cylinder is shown in Figure 14.

4.1. Height Optimization of the Rubber Cylinder. According to the relevant literature, the height of upper and lower rubber cylinders is the same in the design of rubber cylinder assembly, and the height of the middle rubber cylinder is less than that of upper and lower rubber cylinders.

\subsubsection{Height Optimization of Upper and Lower Rubber} Cylinders. For upper and lower rubber cylinder materials, the height $H$ of the rubber cylinder is taken as the design variable under the inclination angle at $45^{\circ}$ of the rubber cylinder and seating load of $70 \mathrm{kN}$. The height of the rubber cylinder varies from $20 \mathrm{~mm}$ to $170 \mathrm{~mm}$.

The maximum stress on the contact surface between the rubber cylinder and the inner wall of the casing is extracted, and the curve of the maximum contact pressure between the rubber cylinder and the casing with the height of the rubber cylinder is obtained, as shown in Figure 15.

According to Figure 15, it can be seen that when the height of the rubber cylinder is $20 \mathrm{~mm}$, only one part of the rubber cylinder after deformation contacts with the inner wall of the casing. From $30 \mathrm{~mm}$ to $60 \mathrm{~mm}$ height, the maximum contact pressure increases obviously with the 


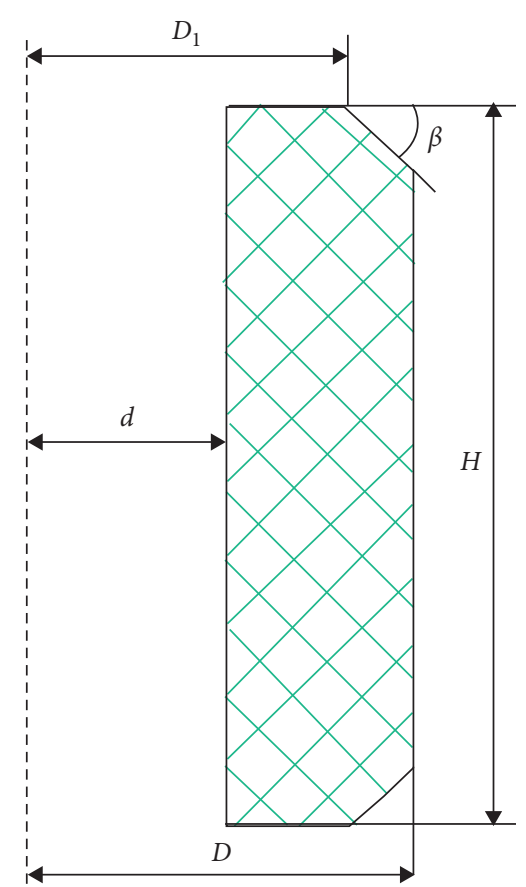

Figure 14: The design size diagram of the rubber cylinder.

increase of height, and the contact length between the rubber cylinder and the casing also increases, the sealing effect increases significantly, but the shoulder has the trend of outflow; from $60 \mathrm{~mm}$ to $170 \mathrm{~mm}$ height, with the increase of height, the maximum contact pressure decreases accordingly. Starting from $70 \mathrm{~mm}$, the gap between the inner wall of the rubber cylinder and the central tube is large and not compacted, which reduces the sealing effect and aggravates the shoulder protrusion. In conclusion, in order to improve the sealing performance of rubber cylinders, the height of upper and lower rubber cylinders should be preferentially selected about $60 \mathrm{~mm}$.

4.1.2. Height Optimization of the Middle Rubber Cylinder. Under the condition of camber angle of $45^{\circ}$ and $70 \mathrm{kN}$ seating load, the height of the middle rubber cylinder is taken as the design variable, and the height $H$ varies from $20 \mathrm{~mm}$ to $160 \mathrm{~mm}$.

The maximum stress on the contact surface between the rubber cylinder and the inner wall of the casing is extracted, and the curve of the maximum contact pressure between the rubber cylinder and the casing with the height of the rubber cylinder is obtained, as shown in Figure 16.

It can be seen that when the height of the rubber cylinder is $20 \mathrm{~mm}$ as shown in Figure 16, the axial compression deformation of the rubber cylinder is relatively small, and the contact length between the rubber cylinder and the casing is relatively small; thus, the contact pressure is relatively small; when the height of the rubber cylinder increases to $30 \mathrm{~mm}$, the contact pressure increases significantly, which makes the sealing effect better. From $30 \mathrm{~mm}$ to $160 \mathrm{~mm}$, the maximum contact pressure decreases with the increase of height, the sealing effect decreases, and

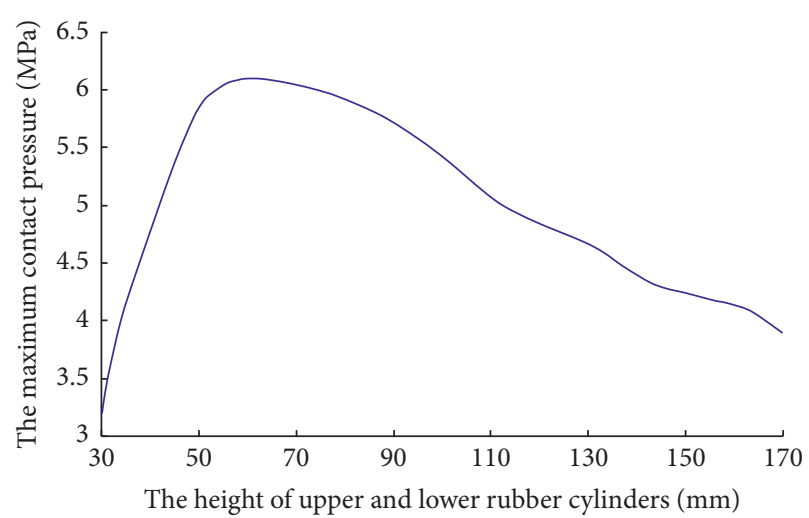

FIgURE 15: The relationship between the maximum contact stress and the height of the rubber cylinder.

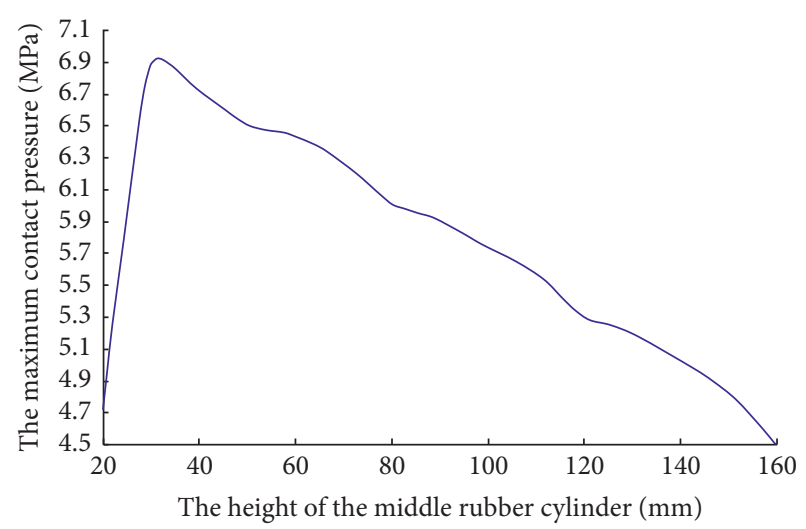

Figure 16: The relationship between the maximum contact stress and the height of the rubber cylinder.

the rubber cylinder is not compacted from $100 \mathrm{~mm}$. In addition, the shoulder protrusion phenomenon is also serious with the increase of height. Because the heights of $30 \mathrm{~mm}$ and $40 \mathrm{~mm}$ are relatively short, although the contact pressure is relatively large, it is easy to crush when the load increases. When the rubber cylinder is $50 \mathrm{~mm}$, the rubber cylinder is compacted, and the sealing pressure is large, so the sealing effect is better. In summary, the height of the middle rubber cylinder is about $50 \mathrm{~mm}$.

4.2. Thickness Optimization of the Rubber Cylinder. Under the condition of camber angle of $45^{\circ}$ and $70 \mathrm{kN}$ seating load for a single rubber cylinder, the height of the rubber cylinder is taken as the design variable, and the height $H$ varies from $20 \mathrm{~mm}$ to $160 \mathrm{~mm}$.

The maximum contact pressure between the rubber tube and the casing with different thicknesses through analysis is obtained as shown in Figure 17.

From Figure 17, it can be seen that, from $15 \mathrm{~mm}$ to $21 \mathrm{~mm}$, the maximum contact pressure increases obviously with the increase of thickness, and the rubber cylinder is compacted, the sealing effect is improved significantly, and the degree of shoulder protrusion is also increased, but there is little difference and within a reasonable range; from $21 \mathrm{~mm}$ 


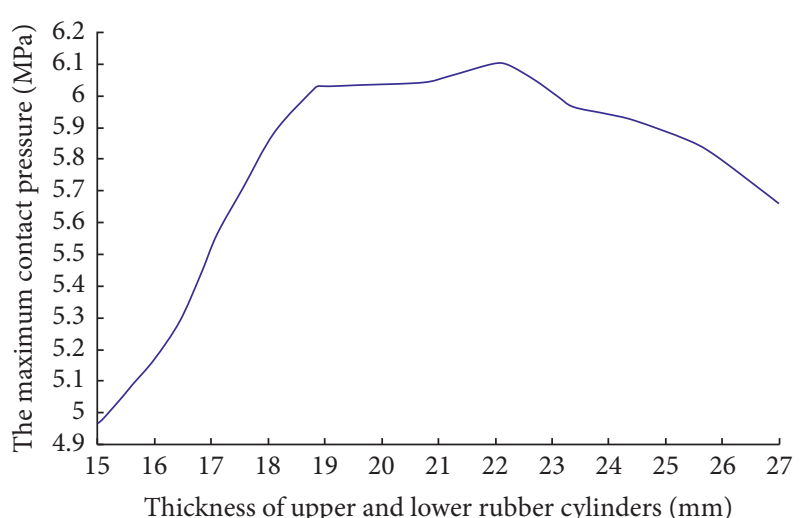

FIGURE 17: The relationship between the thickness of upper and down rubber cylinders and the maximum contact pressure.

to $25 \mathrm{~mm}$, the maximum contact pressure follows with the increase of thickness. With the decrease of thickness, the sealing effect decreases, and the degree of shoulder protrusion decreases, but the effect is not significant. Generally speaking, the thickness of upper and lower rubber cylinders should be about $21 \mathrm{~mm}$.

\subsection{Effect of External Conditions on Sealing Performance of Packers}

4.3.1. Effect of Sealing Load on Sealing Performance of the Rubber Cylinder. For the optimized rubber cylinder seal assembly, the force generated by the contact between the rubber cylinder and the casing is simulated by numerical simulation software. The upper and lower ends of the casing and the central pipe (tubing) are fixed, and the lower diaphragm ring is fixed. The seating pressures of $10 \mathrm{kN}, 20 \mathrm{kN}$, $30 \mathrm{kN}, 40 \mathrm{kN}, 50 \mathrm{kN}$, and $60 \mathrm{kN}$ are applied to the upper diaphragm ring, respectively. The variation curves of Figure 18 are obtained by analysis. It can be seen that the maximum contact pressure between the rubber cylinder and the casing increases linearly with the increase of the seating load when the seating force is greater than $30 \mathrm{kN}$.

4.3.2. Effect of Different Annulus Sizes on the Sealing Performance of Rubber Cylinders. For the optimized packer, the size of the annular space gap is different when the casing type is different. Then, the influence of the annular gap on the performance of the packer is simulated by finite element software. The annular space gap (the space of inner diameter of the casing and outer diameter of the rubber cylinder) is $1 \mathrm{~mm}, 2 \mathrm{~mm}, 3 \mathrm{~mm}, 4 \mathrm{~mm}, 5 \mathrm{~mm}, 6 \mathrm{~mm}, 7 \mathrm{~mm}$, and $8 \mathrm{~mm}$, respectively. Through analysis, the variation curves between the annular space gap of different casing and the maximum axial compression of the rubber cylinder are obtained, as shown in Figure 19.

From Figure 19, it can be seen that, with the increase of the gap between the inner diameter of the casing and the outer diameter of the rubber cylinder, the maximum axial compression of the rubber cylinder has a significant change. Because the middle rubber cylinder is relatively soft, when

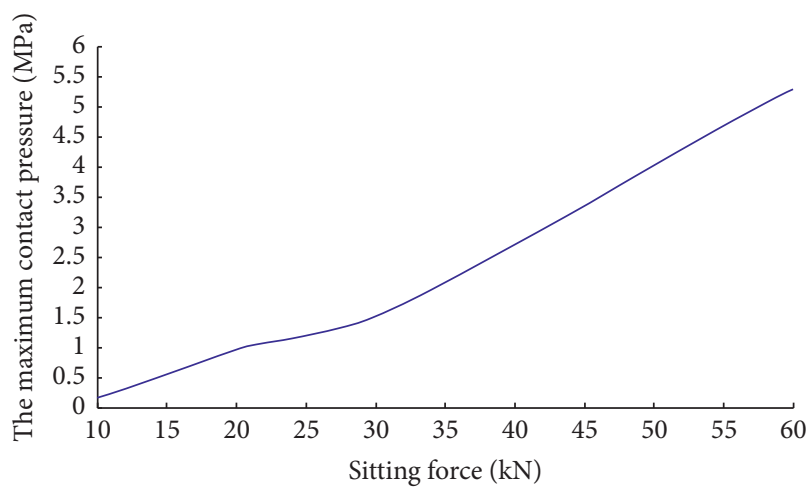

FIgURE 18: The maximum contact pressure curve of the rubber cylinder under different loads.

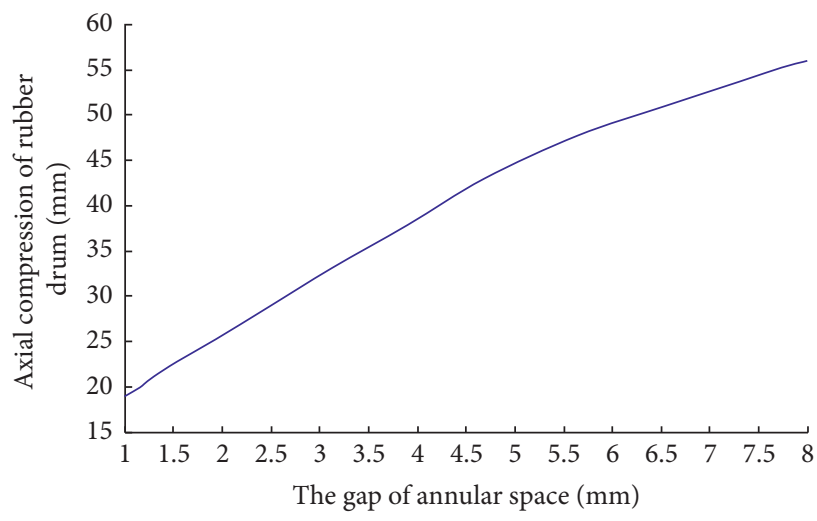

FIgURE 19: The maximum axial compression curve of the rubber cylinder under different gaps of annular.

the gap is $7 \mathrm{~mm}$, the inner side of the middle rubber cylinder begins to appear larger deformation, which is very disadvantageous and seriously affects the life of the rubber cylinder.

It can also be seen from Figure 20 that when the annular space gap is less than $7 \mathrm{~mm}$, the upper rubber cylinder plays the main role of sealing. When the annular space gap is greater than $7 \mathrm{~mm}$, the contact pressure of the middle rubber cylinder begins to be greater than that of the upper rubber cylinder and begins to play the sealing role together with the upper rubber cylinder.

In summary, different annular space gap sizes, in other words, different casing types or different packer outer diameters will affect the sealing performance of the packer. Considering the service life of the rubber cylinder, the annular space gap should not exceed $7 \mathrm{~mm}$, so the upper rubber cylinder plays the main sealing role; considering the sealing effect, it is obvious that the contact pressure of the annular space gap is the greatest around $2 \mathrm{~mm}$, so the effect is the best. At the same time, the maximum Mises stress of the rubber cylinder is smaller when the gap is about $2 \mathrm{~mm}$, which can better guarantee the rubber cylinder's performance. Therefore, the optimal annular space gap of this kind of packer is about $2 \mathrm{~mm}$.

The results show that the sealing performance of the packer is better when the inclination angle of the rubber 


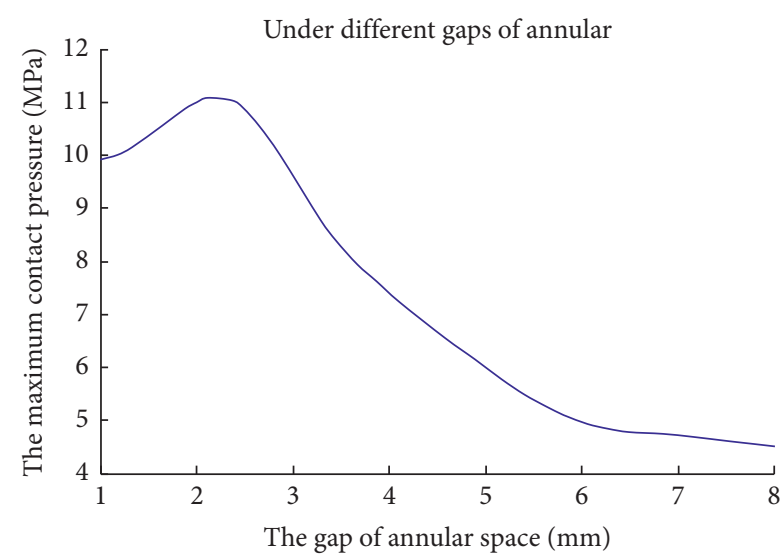

FIgURE 20: The maximum contact pressure curve of the rubber cylinder under different gaps of annular.

cylinder is $45^{\circ}$, the height of the upper and lower rubber cylinder is $60 \mathrm{~mm}$, the height of the middle rubber cylinder is $50 \mathrm{~mm}$, and the thickness of the rubber cylinder is $21 \mathrm{~mm}$. With the increase of seating load, the contact pressure between the rubber cylinder and the casing increases continuously. The maximum contact pressure of the rubber cylinder increases with the increase of the annular space gap. It shows the trend of first increasing and then decreasing and reaches the maximum when the gap is about $2 \mathrm{~mm}$.

This provides a theoretical basis for the preliminary seating of the structural dimensions of rubber cylinders by analyzing the stress situation of rubber cylinders. Initially, the inner diameter of the rubber cylinder is $104 \mathrm{~mm}$, the outer diameter of the rubber cylinder is $146 \mathrm{~mm}$, and the height of the rubber cylinder is $60 \mathrm{~mm}$. The angle of the rubber cylinder is $45^{\circ}$, the height of the upper and lower rubber cylinder is $60 \mathrm{~mm}$, the height of the middle rubber cylinder is $50 \mathrm{~mm}$, and the thickness of the rubber cylinder is $21 \mathrm{~mm}$.

\section{Test Simulation of New Packer Rubber}

This section mainly aims at the pressure-bearing capacity and sealing performance test of the new rubber cylinder, using $7^{\prime \prime}$ casing (inner diameter $166.1 \mathrm{~mm}$, central diameter $88.5 \mathrm{~mm}$, and guide ring outer diameter $144.3 \mathrm{~mm}$ ), under $150 \mathrm{C}, 10,000$ Psi conditions of sealing pressure.

Test conditions: simulated test temperature: $150^{\circ} \mathrm{C} \pm 5^{\circ} \mathrm{C}$; maximum pressure: $10,000 \mathrm{Psi}$; simulated casing specification: 20 Pounds.

Test equipment: sealing equipment unit: $160 \mathrm{~T}$ rubber vulcanizer, maximum pressure: $160 \mathrm{~T}$. Pressure accuracy: $1 \mathrm{~T}$; pressure equipment unit: 27,000 Psi pneumatic high-pressure pump; pressure display accuracy: 200 Psi; simulated working unit: self-designed test tooling for simulated working conditions. System pressure drop: 200 Psi/15 min; heating unit: selfdesigned oil bath heater. Temperature control error: $\pm 5^{\circ} \mathrm{C}$; test medium: ISO/TS 16949; the viscosity of high-temperature heat conducting oil is $-30 \mathrm{CST}$ at $40^{\circ} \mathrm{C}$.

The whole test process of seal pressure of $7^{\prime \prime}$ casing (inner diameter $166.1 \mathrm{~mm}$, central diameter $88.5 \mathrm{~mm}$, and guide ring outer diameter $144.3 \mathrm{~mm}$ ) under $150 \mathrm{C}$ and 10,000 Psi conditions is as follows.

The assembly parts are tightened everywhere and then connected with the pressing equipment to test the 1 \# rubber sleeve as shown in Figure 21. The seating pressure of $8 \mathrm{~T}$ is applied slowly, and the pressing test is carried out after 1 minute of pressure stabilization. After 3 minutes of pressure stabilization, the pressure drops to $300 \mathrm{Psi}$; then, the pressure is hit to $4,000 \mathrm{Psi}$, and the pressure drops to 200 Psi after 2 minutes of pressure stabilization. Continue to increase the pressure of the rubber cylinder until it reaches 10,000 Psi. After 6 minutes of pressure stabilization to 10,000 Psi, the pressure drop was 100 Psi. 2\# rubber sleeve also uses the same experimental process. The curve of two pressing tests is shown in Figure 22.

After pressure relief, the elasticity of the rubber sleeve is good, and then the rubber cylinder is taken out. There is a circle of shear marks on the shoulder of the upper rubber sleeve, which is relatively intact as a whole, as shown in Figure 23.

\section{The Whole Performance Test Process of the Packer}

After assembling the removable packer and the pressure testing tooling, the casing is put into the casing as shown in Figure 24, the pin can be cut by $6 \mathrm{MPa}$ pressure, the seat seal can be started, and then three times of pressure testing are carried out. The pressure is $10 \mathrm{MPa}-21 \mathrm{MPa}-70 \mathrm{MPa}$, and the temperature varies between 60 and $140^{\circ} \mathrm{C}$, respectively. The pressure is stabilized for a certain period of time, and the temperature and seal of the three tests are observed step by step. Seating pressure and bearing pressure are stable in the temperature range. Figure 24 shows a physical drawing of the assembly equipment and the pressure gauge.

In the first test, it was found from the temperature, seating pressure, and bearing pressure curves as shown in Figure 25. There are bearing pressure stabilization stages in each stage. The temperature drops by about $12^{\circ} \mathrm{C}$, and the temperature drops by about $3 \mathrm{MPa}$. When the temperature is $112^{\circ} \mathrm{C}-126^{\circ} \mathrm{C}$, the seating pressure and bearing pressure can be stabilized at about $70-75 \mathrm{MPa}$, and the seating time is 14 minutes, which shows that the sealing performance is stable in this temperature range.

The second test found the seating pressure and bearing pressure curve which found that the seating pressure was lower than the bearing pressure as shown in Figure 26. The bearing pressure could reach $52.5 \mathrm{MPa}$ when the temperature was $130^{\circ} \mathrm{C}-140^{\circ} \mathrm{C}$. The seating pressure was stable at about $18-36 \mathrm{~T}$. The seating pressure was stable, indicating that the sealing performance was stable in this temperature range. There were bearing pressure stabilization stages in all stages, and the temperature was also stable. The bearing pressure can be stabilized at about $52.5 \mathrm{MPa}$, and the seating time is 10 minutes at $132^{\circ} \mathrm{C}$. It shows that the sealing performance is stable, and the bearing pressure can reach $60 \mathrm{MPa}$ in this temperature range.

The third test found the seating pressure and bearing pressure curve which found that the seating pressure is lower 

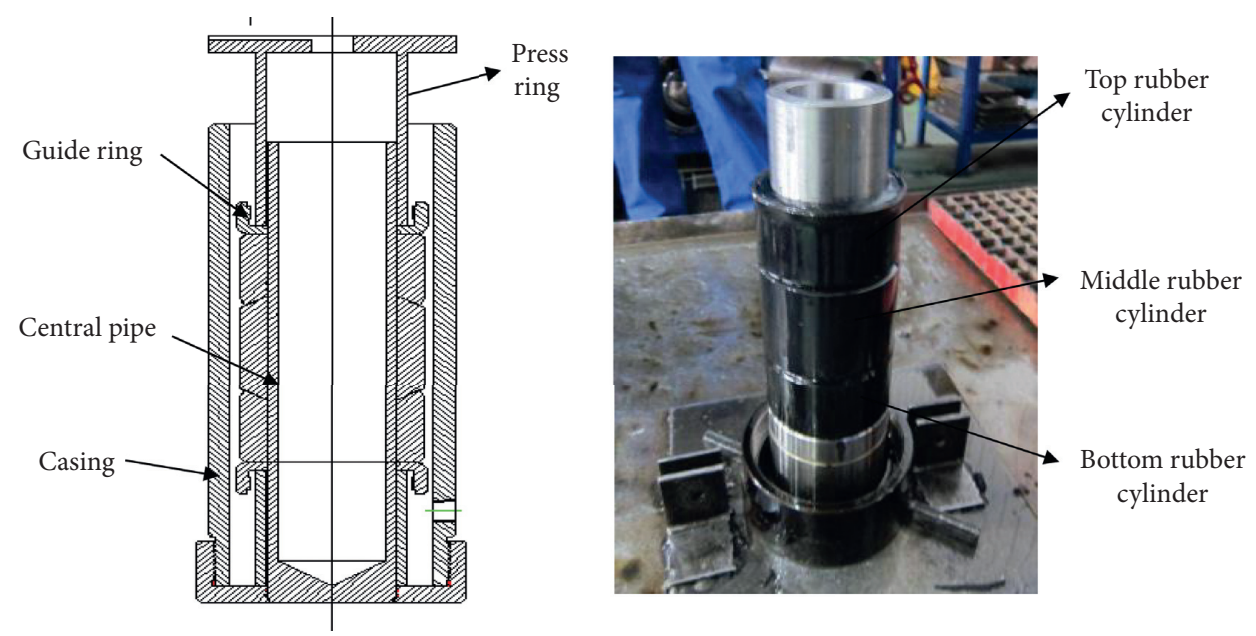

FIGURE 21: Experimental device of pressure-bearing and physical drawing of rubber sleeve.
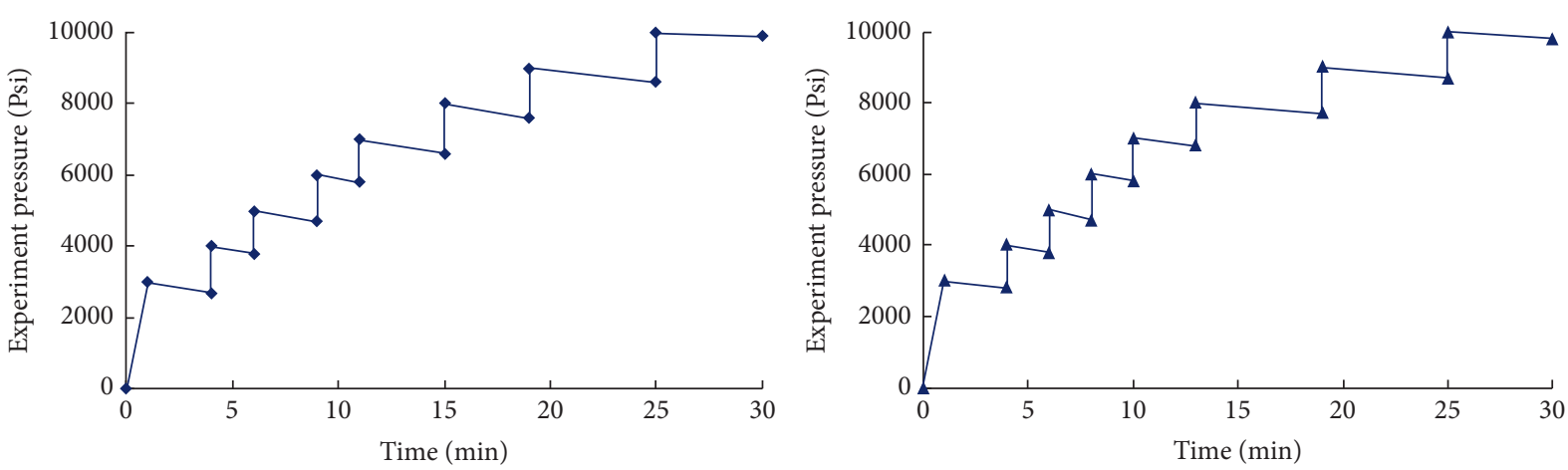

FIgURE 22: Pressure curves of $1 \#$ and 2\# rubber cylinders.

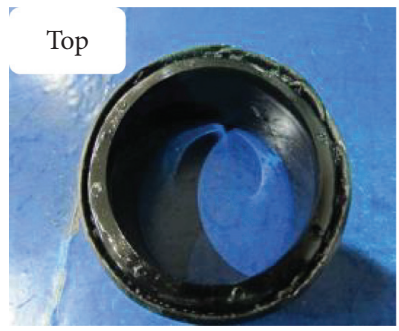

(a)

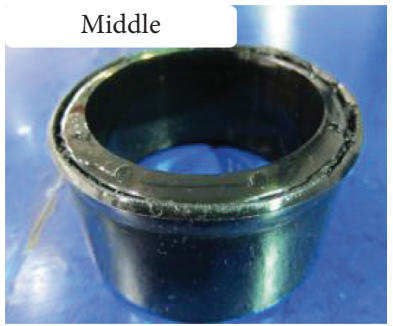

(b)

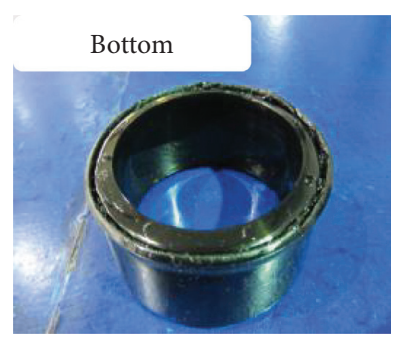

(c)

FIGURE 23: Deformation diagram of 2\# rubber sleeve after pressure.

than the pressure as shown in Figure 27. The pressure can reach $72 \mathrm{MPa}$ when the temperature is $130^{\circ} \mathrm{C}-140^{\circ} \mathrm{C}$, the seating pressure is stable at about $15-20 \mathrm{MPa}$, the seating pressure is stable, the seating and bearing pressure time is 700 minutes, and the temperature varies between $108^{\circ} \mathrm{C}$ and $140^{\circ} \mathrm{C}$. 

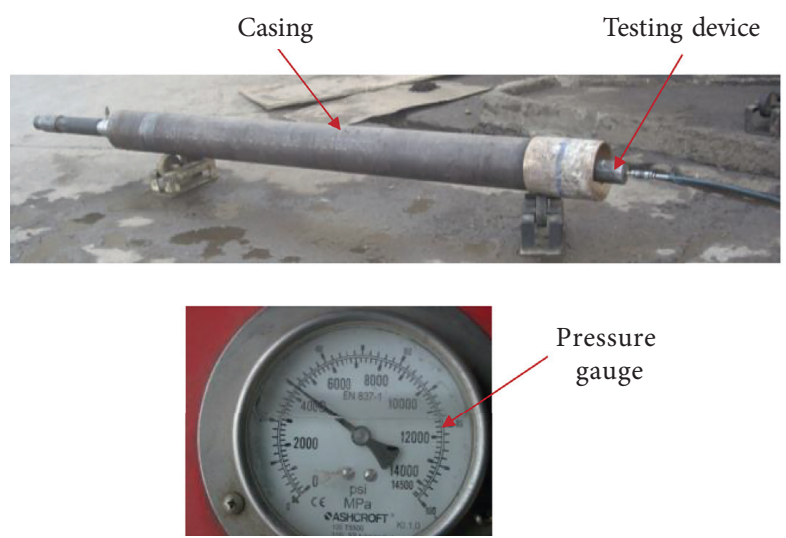

FIGURe 24: Pressure testing device and pressure gauge.

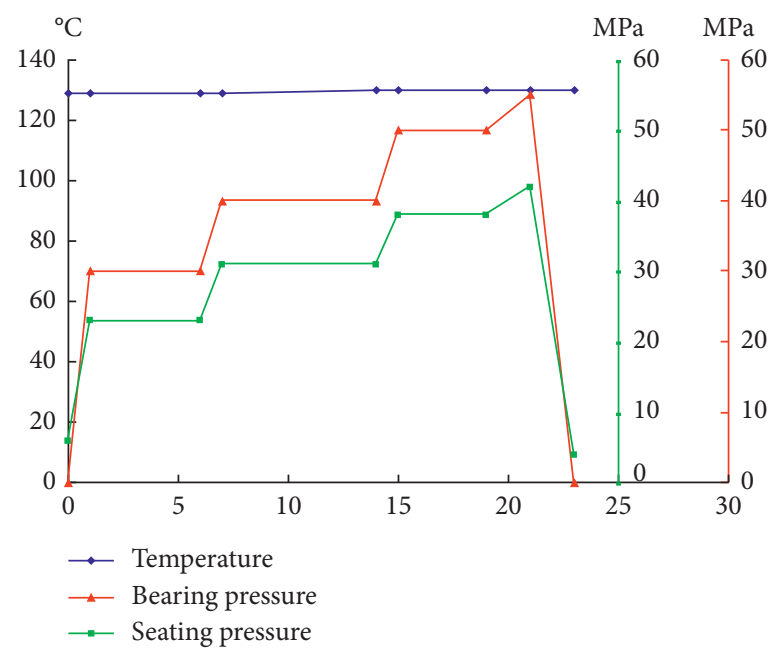

FIGURE 25: Change curve temperature, seating pressure, and bearing pressure.

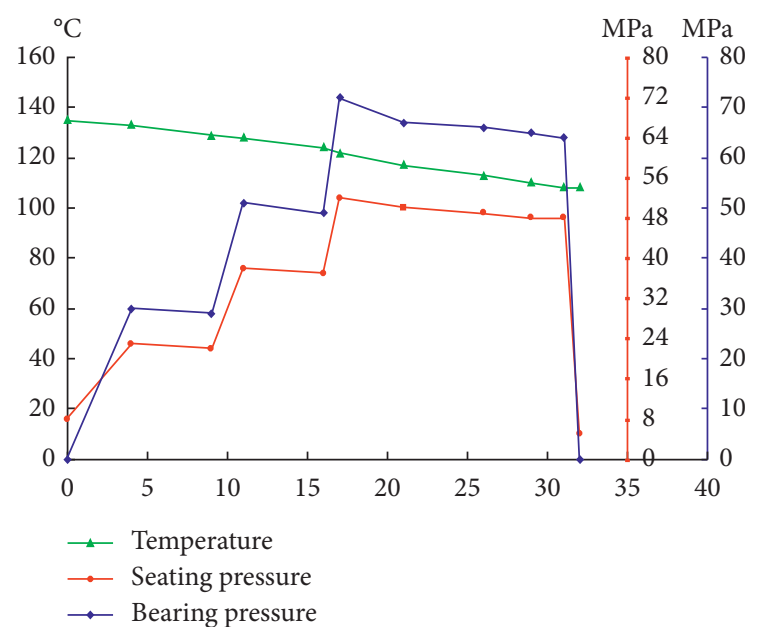

FIgURE 26: Change curve temperature, seating pressure, and bearing pressure.

\section{Conclusions}

In this paper, according to the design of the new seal structure, theoretical calculation and experimental

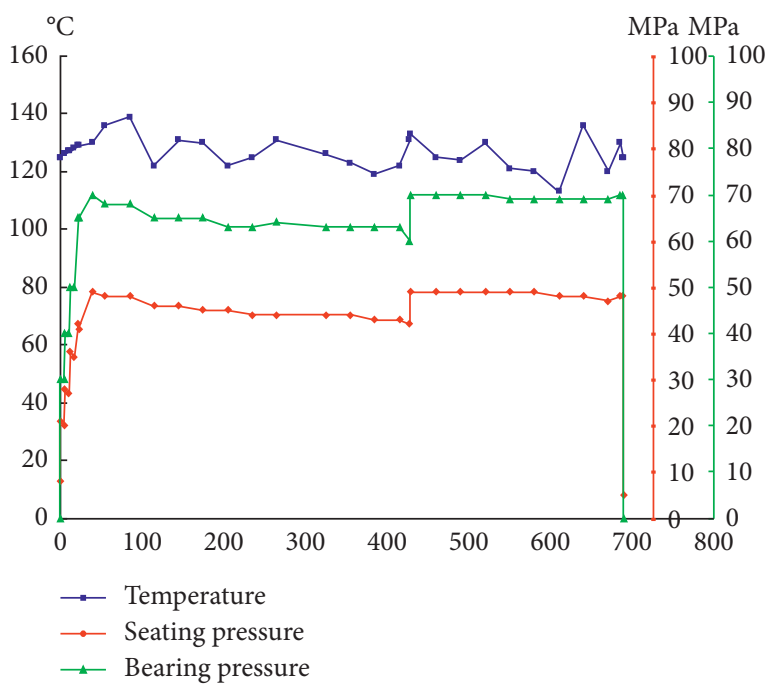

FIgURE 27: Change curve temperature, seating pressure, and bearing pressure.

research are carried out, and the following conclusions are drawn:

(1) When the wellbore and the packer are sealed, the upper rubber cylinder is subjected to greater stress under various working conditions and mainly plays a sealing role

(2) Loading displacement, friction coefficient, and temperature increase will increase the contact pressure between packer rubber and casing wall, and the average contact pressure is greater than the sealing specific pressure

(3) The effective pressure difference between the top and bottom of the rubber cylinder can be maintained by increasing the height of rubber cylinder and the effective sealing length of the rubber cylinder and the well bore

(4) Through sealing performance and pressure test, the sealing effect is stable, and the elasticity of the rubber sleeve is good, which indicates that the newly designed rubber cylinder can meet the sealing pressure of 150 and 10,000 Psi

(5) Through three tests, it is found that the bearing pressure can reach $72 \mathrm{MPa}$, the seating pressure can be stabilized at about $15-20 \mathrm{MPa}$, the seating pressure and the holding time can reach 690 minutes, and the sealing performance of the bearing pressure and the bearing pressure can be stable in the temperature range of $108^{\circ} \mathrm{C}-140^{\circ} \mathrm{C}$

\section{Data Availability}

The data used to support the findings of this study are included within the article.

\section{Conflicts of Interest}

The authors declare no conflicts of interest. 


\section{Acknowledgments}

The authors are grateful for the financial support from the National Natural Science Foundation of China (no. 51974271), Joint Fund Project of the National Natural Science Foundation of China under Grant no. U19A2097, and Key Projects of Young Plant of Science and Technology Innovation of Sichuan (20MZGC0090).

\section{References}

[1] J. Zhang, J. Xie, and H. Zhang, "Production capacity and mining plan optimization of fault/fracture-controlled EGS model in Gonghe Basin," Energy Science Engineering, vol. 7, no. 6, pp. 1-18, 2019.

[2] J. Zhang and R. Xie, "Numerical analysis of mechanical behavior of buried pipes in subsidence area caused by underground mining," Journal of Pressure Vessel Technology, vol. 141, Article ID 021703, 2019.

[3] Y.-F. Chen, M.-M. Liu, S.-H. Hu, and C.-B. Zhou, "NonDarcy's law-based analytical models for data interpretation of high-pressure packer tests in fractured rocks," Engineering Geology, vol. 199, pp. 91-106, 2015.

[4] P. Quinn, J. A. Cherry, and B. L. Parker, "Combined use of straddle packer testing and flute profiling for hydraulic testing in fractured rock boreholes," Journal of Hydrology, vol. 524, pp. 439-454, 2015.

[5] L. Shaohu, G. Feng, W. Xianjin, X. Hui, W. Zhen, and Y. Ting, "Theoretical and experimental research of bearing capacity and fatigue life for coiled tubing under internal pressure," Engineering Failure Analysis, vol. 104, pp. 1133-1142, 2019.

[6] Y. Tang, P. Sun, G. Wang, and W. Li, "Analysis of pressurebearing performance and optimization of structural parameters of the slip in a compression packer," Science Progress, vol. 103, no. 1, 2019.

[7] J. Zhang and J. Xie, "Effect of reservoir's permeability and porosity on the performance of cellular development model for enhanced geothermal system," Renewable Energy, vol. 148, pp. 824-838, 2020.

[8] D. Zhu, Y. Lin, H. Zhang et al., "Corrosion evaluation of packer rubber materials in $\mathrm{CO}_{2}$ injection wells under supercritical conditions," Journal of Petroleum Science and Engineering, vol. 151, pp. 311-317, 2017.

[9] D. Zhu, Y. Lin, H. Ma et al., "Experimental studies on $\mathrm{CO}_{2}$ corrosion of rubber materials for packer under compressive stress in gas wells," Engineering Failure Analysis, vol. 80, pp. 11-23, 2017.

[10] W. Liu, T. Shi, Q. Lu et al., "Failure analysis on fracture of S13Cr-110 tubing," Engineering Failure Analysis, vol. 90, pp. 215-230, 2018.

[11] X. Li, C. P. Tan, and J.-C. Roegiers, "Effects of packer on hydraulic fractures initiated from highly-deviated and horizontal boreholes," International Journal of Rock Mechanics and Mining Science, vol. 34, no. 3-4, 1997.

[12] M. Wang, P. H. S. W. Kulatilake, J. Um, and J. Narvaiz, "Estimation of REV size and three-dimensional hydraulic conductivity tensor for a fractured rock mass through a single well packer test and discrete fracture fluid flow modeling," International Journal of Rock Mechanics and Mining Sciences, vol. 39, no. 7, pp. 887-904, 2002.

[13] X. He, X. Shi, M. Hoch, and C. Gögelein, "Mechanical properties of carbon black filled hydrogenated acrylonitrile butadiene rubber for packer compounds," Polymer Testing, vol. 53, pp. 257-266, 2016.
[14] Z. Tong, Q. Ye, J. Qian, Z. Hao, and L. Wang, "Down-hole isolation towards high-temperature reservoir using packing elements with swellable thermo-plastic vulcanizates," Journal of Petroleum Science and Engineering, vol. 172, pp. 964-975, 2019.

[15] T. Chen, W. Ma, S. Liu, and J. Wu, "Analysis on mechanical influencing factors of fatigue behavior for the packer on pipe ram in snubbing unit," Engineering Failure Analysis, vol. 103, pp. 20-31, 2019.

[16] J.-S. Moon, "Representativeness of jointed rock mass hydraulic conductivity obtained from packer tests for tunnel inflow rate estimate," International Journal of Rock Mechanics and Mining Sciences, vol. 48, no. 5, pp. 836-844, 2011.

[17] W. Liu, T. Shi, S. Li et al., "Failure analysis of a fracture tubing used in the formate annulus protection fluid," Engineering Failure Analysis, vol. 95, pp. 248-262, 2019.

[18] X. Tang, B. Qian, B. Li, Y. Liu, and Y. Zhang, "Development and application of a packer-type drilling-free liner hanger," Natural Gas Industry B, vol. 1, no. 2, pp. 125-128, 2014.

[19] F. Zhang, L. Ding, and X. Yang, "Prediction of pressure between packers of staged fracturing pipe strings in highpressure deep wells and its application," Natural Gas Industry $B$, vol. 2, no. 2-3, pp. 252-256, 2015.

[20] G. Hu, G. Wang, L. Dai, P. Zhang, M. Li, and Y. Fu, "Sealing failure analysis on $\mathrm{V}$-shaped sealing rings of an inserted sealing tool used for multistage fracturing processes," Energies, vol. 11, no. 6, p. 1432, 2018.

[21] D. Dobrotă and G. Dobrotă, "Reducing of energy consumption by improving the reclaiming technology in autoclave of a rubber wastes," Energies, vol. 12, no. 8, p. 1460, 2019.

[22] J. Zhang, J. Xie, and X. Liu, "Numerical evaluation of heat extraction for EGS with tree-shaped wells," International Journal of Heat and Mass Transfer, vol. 134, pp. 296-310, 2019.

[23] Q. Deng, H. Zhang, J. Li, X. Hou, and H. Wang, "Study of downhole shock loads for ultra-deep well perforation and optimization measures," Energies, vol. 12, no. 14, p. 2743, 2019.

[24] Y. Tang, J. Yao, Y. He, P. Sun, and X. jin, "Study on pressurecontrolled sliding sleeve of jet breaking for natural gas hydrate mining based on throttle pressure drop principle," Energy Science and Engineering, 2020.

[25] H.-l. Wang, Simulating Research of Working Behavior for Down-Hole Packer, Southwest Petroleum University, Chengdu, China, 2004.

[26] J.-l. Huang, G.-j. Xie, and L. Zheng-wei, "FEA of hyperelastic rubber material based on Mooney-Rivlin model and Yeoh model," China Rubber Industry, vol. 55, no. 8, pp. 467-471, 2005.

[27] O. H. Yeoh, "Some forms of the strain energy function for rubber," Rubber Chemistry and Technology, vol. 66, no. 5, pp. 754-771, 1993.

[28] J. Zhang and J. Xie, "Investigation of static and dynamic seal performances of a rubber O-ring," Journal of Tribology, vol. 140, no. 4, Article ID 042202, 2018.

[29] L. O. N. G. Lian-chun, D. U. Jia-zheng, Z.-g. Yang et al., "Analysis and optimization of sealing rubber of the packer," Journal of Beijing University of Technology, no. S1, pp. 52-57, 2006.

[30] J. Sun and X. Yang, "Non-linear finite element analysis on the factor of lager deformation of assembled seal rings with compound material," Lubrication Engineering, no. 4, pp. 123-132, 2006.

[31] C. Yang, B. Li, Z. Xu et al., "The evaluation of sealing and reliability of packer rubber based on working temperature," Chinese Journal of Applied Mechanics, vol. 34, no. 6, pp. 1079-1085, 2017. 